http://jmscr.igmpublication.org/home/

ISSN (e)-2347-176x ISSN (p) 2455-0450

crossref DOI: https://dx.doi.org/10.18535/jmscr/v7i7.43

Journal Of Medical Science And Clinical Research

IGM Publication

An Official Publication of IGM Publication

\title{
To assess correlation between carotid intima-media thickness and dyslipidemia in patients with stroke: A case control study
}

\section{Dr Gautam Chand Jingar ${ }^{1}$, Dr Dinesh Parmar $^{2}$, Dr A.K. Jain ${ }^{3}$, Dr Nishant Kamble ${ }^{4}$, Dr Dinesh Kumar ${ }^{5}$, Dr Vivek Lakhawat ${ }^{6}$}

\author{
${ }^{1}$ Senior Resident, Dept. of Medicine, Government Medical College, Barmer \\ ${ }^{2}$ Associate Professor, Dept. of Medicine, Government Medical College, Barmer \\ ${ }^{3}$ Senior Professor \& Unit Head, Dept. of Medicine, Dr. S. N. Medical College, Jodhpur \\ ${ }^{4,5,6}$ Resident, Dept. of Medicine, Dr. S. N. Medical College, Jodhpur \\ *Corresponding Author \\ Dr Dinesh Parmar
}

Associate Professor, Dept. of Medicine, Government Medical College, Barmer, India

\begin{abstract}
Background: Stroke is a major cause of morbidity and mortality worldwide. An early sign of atherosclerosis is hypertrophy of the arterial wall. Increased intima-media thickness (IMT) is a non-invasive marker of arterial wall alteration, which can easily be assessed in the carotid arteries by high-resolution B-mode ultrasound. Hence it was sought to assess correlation between carotid intima-media thickness and dyslipidemia in patients with stroke.

Material \& Methods: The study was conducted at Department of Medicine, in collaboration with Department of Radiology at Dr. S.N.M.C. \& M.D.M. hospital, Jodhpur by selecting 70 patients out of which 50 were clinically and CT Scan proved cases of CVA and 20 are age-sex matched healthy control group, from medical outpatients department and indoor patients admitted to hospital. Case group contain patients of varied age group of both male and female sex who were having Stroke attending the general MOPD and emergency department. Control group included the normal healthy person without any evidence of Stroke and comorbid conditions.

Results: Our study suggest that increased carotid intima-media thickness is more associated with infarct patients whereas in hemorrhage patients CIMT is usually normal. Our study showed that cholesterol, Triglyceride, LDL Cholesterol, LDL/HDL Ratio have positive association with CIMT in infarct with $p$ value $0.025,0.049,0.013 \& 0.003$ respectively which is significant. HDL Cholesterol \& Chol/HDL Ratio had no positive association with CIMT in infarct with $p$ value 0.333, 0.53 respectively which is not significant.

Conclusion: We concluded that CIMT and LDL/HDL ratio can be used as screening test for all persons who are at higher risk to get stroke such as diabetes, hypertension, obesity, smoker etc.

Keywords: Carotid intima-thickness, Infarct, Hemorrhage, Lipid profile.
\end{abstract}

\section{Introduction}

Cerebrovascular accident or stroke is defined as an abrupt onset of neurological deficit that is attributable to a focal vascular cause ${ }^{[1]}$. Stroke is a major cause of morbidity and mortality worldwide. This may result from brain infarction or hemorrhage. It has been estimated that stroke represented $1.2 \%$ of the total deaths in the country when all ages were included. The proportion of stroke death increased with age, and in the oldest 
group (>70 years of age), stroke contributed to $2.4 \%$ of all deaths.

Atherosclerosis is a multi-stage process that progresses through a series of structural and functional changes taking place in vessel wall culminating into manifest cerebrovascular disease. Long, latent phase of atherosclerosis provides us with ample opportunity to identify this process at an early stage, thus facilitating primary prevention. In last few years, several new noninvasive tools have emerged that can detect atherosclerosis in its sub clinical phase. Carotid intima-media thickness (IMT) and Dyslipidemia are two such promising non-invasive tools. While carotid IMT is a marker of structural aspect of atherosclerosis, dyslipidemia reflects its risk factor. Arterial disease does not begin with the first clinical event but develops long before without symptom, supporting the idea to extrapolate the high prognostic performance of clinical arterial disease to sub clinical disease and motivating much biotechnological medical $\operatorname{research}^{[2-3]}$.

Traditional risk factors are poor screening tests for cerebrovascular disease, whereas clinical arterial disease represents its strongest predictor. This raises the question whether sub clinical arterial disease may also predict cerebrovascular disease. Incidence of cerebrovascular event associated with the absence or presence of atherosclerosis as defined by dichotomous characterization of the following markers: low or high intimamediathickness or the absence or presence of plaque. Yearly incidence was $<1 \%$ in the absence of atherosclerosis regardless of the marker used. The relation between clinically overt arterial disease, such as angina, transient ischemic attack, stroke, or myocardial infarct, and yearly incidence of subsequent events reported in the literature prolonged the dose-response curve of sub clinical disease. Therefore, detection of arterial disease, not only clinically overt but also sub clinical asymptomatic, is a worthwhile screening test for future cerebrovascular accidents.
Some risk factors such as smoking, diabetes, hypertension and atrial fibrillation have been recognized as independently related to stroke occurrence, the predictive role of lipid profile has not yet been well established ${ }^{[4]}$. Many of the previous clinical investigations have suggested that increased serum cholesterol is a risk factor for ischemic stroke. Its role in Intracerebral hemorrhage ( $\mathrm{ICH})$, however, is not clear. Few studies have indicated hypercholesterolemia as a risk factor for $\mathrm{ICH}^{[5]}$.

An early sign of atherosclerosis is hypertrophy of the arterial wall. Increased intima-media thickness (IMT) is a non-invasive marker of arterial wall alteration, which can easily be assessed in the carotid arteries by high-resolution B-mode ultrasound. Carotid IMT correlates with other risk factors such as systolic blood pressure, serum lipids and smoking, as well as being positively linked to the presence and extend of cerebral artery disease in both women and men. The demonstration of a correlation between IMT and cardiovascular events such as stroke and myocardial infarction in clinical studies of atherosclerosis progression and cardiovascular outcomes have led to FDA accepting 2D ultrasound as a valid technique in clinical studies of atherosclerosis. Regression or slowing of progression of increased carotid IMT by various antihypertensive and lipid-lowering drugs agents have been reported. In addition to carotid IMT measurement as a predictive value of future vascular events the presence of plaques or stenosis in the carotid artery tree increases drastically the risk for cerebrovascular events.

Carotid intima-media thickness and dyslipidemia are markers of atherosclerosis and have been shown to reliably predict presence and extent of atherosclerotic vascular disease. However, studies examining their association with each other have shown inconsistent results. Hence it was sought to assess correlation between carotid intima-media thickness and dyslipidemia in patients with stroke. 


\section{Material \& Methods}

The study was conducted at Department of Medicine, in collaboration with Department of Radiology at Dr. S.N.M.C. \& M.D.M. hospital, Jodhpur by selecting 70 patients out of which 50 were clinically and CT Scan proved cases of CVA and 20 are age-sex matched healthy control group, from medical outpatients department and indoor patients admitted to hospital.

\section{Study Population}

The study contained two group of patients belonging to western Rajasthan by geographical distribution-case and control group. Case group contain patients of varied age group of both male and female sex who were having Stroke attending the general MOPD and emergency department.

Control group included the normal healthy person without any evidence of Stroke and comorbid conditions.

\section{Inclusion Criteria}

All cases of Stroke attending medicine outdoor and patients who were admitted to indoor.

\section{Exclusion Criteria}

Patients with:

1. Neurological deficits secondary to epilepsy,

2. Infective or metastatic disorder,

3. Atrial fibrilation

4. Pre-existing severe cognitive disorder Intracranial neoplasm.

5. Patients suffering from meningitis, neurocysticercosis

6. Head Injury.

7. Intracranial aneurysms.

8. AV malformations.

9. Any cardiac source of embolism.

10. H/O intake of any lipid lowering drugs.

11. Coronary Heart disease

12. Hypercoagulable disorders

13. Vasculitis

14. Hypothyroidism

Clinical Examination: History and Physical Examination with examination of the Nervous System in details.
Biochemical Tests: Lipid Profile (after $14 \mathrm{hrs}$ overnight fasting) done by Beckman coulter AU680 fully Auto-analyser.

Carotid Doppler Study was performed with 7.5 $10 \mathrm{MHz}$ linear transducers with patient in supine position. High resolution B mode, Colour Doppler Ultrasonography of both carotid arteries performed with an ultrasound machine Prosound Alpha manufactured by ALOKA(as available in MDM Hospital). After the carotid arteries located by transverse scans the probe rotated $90^{\circ}$ to obtain and record a longitudinal image of the anterior and posterior walls. Three sites were selected in each carotid artery. CIMT was measured on the frozen frame of a suitable longitudinal image with the image magnified to achieve a higher resolution of detail. The first reading was taken $1 \mathrm{~cm}$ proximal to the carotid bulb while the second at a maximum diameter of the carotid bulb. The third reading was taken $1 \mathrm{~cm}$ distal to the carotid bulb along the internal carotid artery. For all three sites, both near wall and far wall measurements were taken. The average of each artery was computed taking into all six readings as $(A+B+C+D+E+F) / 6$, where $A=$ far wall of CCA, $B=$ nearwall of CCA, $C=$ far wall of carotid bulb, $D=$ near wall of carotid bulb, $E=$ far wall of internal carotid artery (ICA), $F=$ near wall of ICA.

Plain/ Contrast CT scan (16/64 slice) of Brain or MRI (1.5Tesla)/ MR Angoigram (if indicated) of Brain (as available in MDM Hospital).

An informed consent was taken from the patients regarding participation in the study. In the selected patients appropriate history regarding duration of disease and treatment was elicited. Detailed clinical examination performed. The patients were subjected to Colour Doppler of carotid artery by the Colour Doppler machine available with the Department of Radiology at MDM Hospital and Serum Lipid profile analysed.

\section{Results}

Our study showed that CVA male -female ratio $\approx 1.4: 1$ while in control male-female ratio $\approx 1.6: 1$, age wise in CVA no of patient are more in 51-70 


\section{JMSCR Vol||07||Issue ||07||Page 216-222||July}

age group and in 51-70 age group male were affected more as compared to female, in $\geq 70$ age group female are affected more as compared to male (table 1). In age group 31-50 and 51-70 CIMT is significant $(\mathrm{p}<0.05)$ but in age group above 70year CIMT is not significant(p >0.05) (table 2).

Our study suggest that increased carotid intimamedia thickness is more associated with infarct patients whereas in hemorrhage patients CIMT is usually normal (table 3 ).

In this, cholesterol, Triglyceride, LDL Cholesterol, LDL/HDL Ratio have positive association with CIMT in stroke with $\mathrm{p}$ value $0.001,0.035,0.001 \& 0.002$ respectively which is significant. HDL Cholesterol \& Chol/HDL Ratio had no positive association with CIMT in stroke with $\mathrm{p}$ value $0.554,0.907$ respectively which is not significant (table 4).

Our study showed that cholesterol, Triglyceride, LDL Cholesterol, LDL/HDL Ratio have positive association with CIMT in infarct with $\mathrm{p}$ value $0.025,0.049,0.013 \& 0.003$ respectively which is significant.

HDL Cholesterol \& Chol/HDL Ratio had no positive association with CIMT in infarct with $\mathrm{p}$ value $0.333,0.53$ respectively which is not significant (table 5). Lipid profile had no positive correlation with CIMT in haemorrhage patients (table 6).

Table 1: Age-Sex Wise Distribution of CVA Patients and Control Group

\begin{tabular}{|c|c|c|c|c|c|c|c|c|c|}
\hline \multirow{3}{*}{$\begin{array}{l}\text { AGE } \\
\text { (years) }\end{array}$} & \multicolumn{3}{|c|}{ CASE } & \multicolumn{3}{|c|}{ CONTROL } & \multicolumn{3}{|c|}{ TOTAL } \\
\hline & Male \% & Female \% & T \% & Male \% & Female \% & T \% & Male \% & Female \% & T \% \\
\hline & $\mathrm{n}=\mathbf{2 7}$ & $n=23$ & $\mathrm{n}=50$ & $n=13$ & $n=7$ & $n=20$ & $n=40$ & $n=30$ & $n=70$ \\
\hline $31-50$ & $9(33.3)$ & $6(26.0)$ & $15(30)$ & $5(38.5)$ & $2(28.6)$ & $7(35)$ & $14(40)$ & $8(26.7)$ & $22(31.4)$ \\
\hline $51-70$ & $13(48.1)$ & $9(39.1)$ & $22(44)$ & $6(46.1)$ & $3(42.8)$ & $9(45)$ & $19(42.5)$ & $12(40.0)$ & $31(44.2)$ \\
\hline$>70$ & $5(18.5)$ & $8(37.8)$ & $13(26)$ & $2(15.4)$ & $2(28.6)$ & $4(20)$ & $7(17.5)$ & $10(33.3)$ & $17(24.3)$ \\
\hline $\begin{array}{l}\text { Mean Age } \\
\text { (year) }\end{array}$ & $58.6 \pm 14.5$ & $62.8 \pm 15.7$ & $60.7 \pm 15.6$ & $53.7 \pm 15.8$ & $54.7 \pm 15.9$ & $54.2 \pm 16.3$ & $56.2 \pm 14.8$ & $58.7 \pm 15.1$ & $57.4 \pm 15.7$ \\
\hline
\end{tabular}

Table 2: Age Wise Distribution of CIMT in CVA Patients and Control Group

\begin{tabular}{|l|c|c|c|}
\hline Age Group & Case & Control & p value \\
\hline $31-50$ & $0.79 \pm 0.09$ & $0.66 \pm 0.01$ & $<0.05$ \\
\hline $51-70$ & $0.96 \pm 0.14$ & $0.70 \pm 0.23$ & $<0.05$ \\
\hline$>70$ & $1.03 \pm 0.16$ & $0.73 \pm 0.13$ & $>0.05$ \\
\hline
\end{tabular}

Table 3: Distribution of Stroke Group Population in Infarct and Hemorrhage with Carotid Intima-Media Thickness (CIMT)

\begin{tabular}{|l|c|c|c|}
\hline \multirow{2}{*}{} & \multicolumn{2}{|c|}{ CIMT } & \multirow{2}{*}{ p value } \\
\cline { 2 - 3 } & $<\mathbf{0 . 9} \mathbf{m m}$ & $\mathbf{> 0 . 9 m m}$ & \\
\hline Infarct & 8 & 24 & $<0.001$ \\
\hline Hemorrhage & 11 & 7 & \\
\hline
\end{tabular}

Table 4: Comparison of Cholesterol with CIMT in Stroke

\begin{tabular}{|l|c|c|c|c|}
\hline \multirow{2}{*}{ Lipid Profile } & \multirow{2}{*}{ Values } & \multicolumn{2}{|c|}{ CIMT } & \multirow{2}{*}{ p value } \\
\cline { 2 - 4 } & & $<\mathbf{0 . 9 m m}$ & $\mathbf{0 . 9 m m}$ & \\
\hline \multirow{2}{*}{ Cholesterol } & $<200 \mathrm{mg} / \mathrm{dL}$ & 11 & 2 & \multirow{2}{*}{0.001} \\
\cline { 2 - 4 } & $\geq 200 \mathrm{mg} / \mathrm{dL}$ & 12 & 25 & \\
\hline \multirow{2}{*}{ LDiglyceride } & $<150 \mathrm{mg} / \mathrm{dL}$ & 17 & 12 & \multirow{2}{*}{0.035} \\
\cline { 2 - 4 } & $\geq 150 \mathrm{mg} / \mathrm{dL}$ & 6 & 15 & \\
\hline \multirow{2}{*}{ HDL Cholesterol } & $<130 \mathrm{mg} / \mathrm{dL}$ & 9 & 1 & \multirow{2}{*}{0.001} \\
\cline { 2 - 4 } & $\geq 130 \mathrm{mg} / \mathrm{dL}$ & 14 & 26 & \\
\hline \multirow{2}{*}{ LDL/HDL Ratio } & $<40 \mathrm{mg} / \mathrm{dL}$ & 10 & 14 & \multirow{2}{*}{0.554} \\
\cline { 2 - 4 } & $\geq 40 \mathrm{mg} / \mathrm{dL}$ & 13 & 13 & \\
\cline { 2 - 4 } & $<3.5$ & 15 & 6 & 0.002 \\
\hline \multirow{2}{*}{ Chol/HDL Ratio } & $\geq 3.5$ & 8 & 21 & 0.907 \\
\cline { 2 - 4 } & $\geq 3.5$ & 15 & 6 & \\
\hline
\end{tabular}


Table 5: Comparison of Lipid Profile with CIMT in Infarct

\begin{tabular}{|c|c|c|c|c|}
\hline \multirow[t]{2}{*}{ Lipid profile parameter } & \multirow[t]{2}{*}{ Level/Ratio } & \multicolumn{2}{|c|}{ CIMT } & \multirow[t]{2}{*}{$p$ value } \\
\hline & & $<0.9 \mathrm{~mm}$ & $>0.9 \mathrm{~mm}$ & \\
\hline \multirow{2}{*}{ Cholesterol } & $<200 \mathrm{mg} / \mathrm{dL}$ & 3 & 0 & \multirow{2}{*}{0.025} \\
\hline & $\geq 200 \mathrm{mg} / \mathrm{dL}$ & 6 & 23 & \\
\hline \multirow[t]{2}{*}{ Triglyceride } & $<150 \mathrm{mg} / \mathrm{dL}$ & 7 & 9 & \multirow[t]{2}{*}{0.049} \\
\hline & $\geq 150 \mathrm{mg} / \mathrm{dL}$ & 2 & 14 & \\
\hline \multirow[t]{2}{*}{ LDL } & $<130 \mathrm{mg} / \mathrm{dL}$ & 4 & 0 & \multirow[t]{2}{*}{0.013} \\
\hline & $\geq 130 \mathrm{mg} / \mathrm{dL}$ & 5 & 23 & \\
\hline \multirow[t]{2}{*}{ HDL } & $<40 \mathrm{mg} / \mathrm{dL}$ & 3 & 12 & \multirow[t]{2}{*}{0.336} \\
\hline & $\geq 40 \mathrm{mg} / \mathrm{dL}$ & 6 & 11 & \\
\hline \multirow[t]{2}{*}{ LDL/HDL } & $<3.5$ & 7 & 5 & \multirow[t]{2}{*}{0.003} \\
\hline & $\geq 3.5$ & 2 & 18 & \\
\hline \multirow[t]{2}{*}{ Chol/HDL } & $<3.5$ & 0 & 1 & \multirow[t]{2}{*}{0.53} \\
\hline & $\geq 3.5$ & 9 & 22 & \\
\hline
\end{tabular}

Table 6: Comparison of Lipid Profile with CIMT in Hemorrhage

\begin{tabular}{|c|c|c|c|c|}
\hline \multirow[t]{2}{*}{ Lipid profile parameter } & \multirow[t]{2}{*}{ Level/Ratio } & \multicolumn{2}{|c|}{ CIMT } & \multirow{2}{*}{ p value } \\
\hline & & $<0.9 \mathrm{~mm}$ & $>0.9 \mathrm{~mm}$ & \\
\hline \multirow[t]{2}{*}{ Cholesterol } & $<200 \mathrm{mg} / \mathrm{dL}$ & 8 & 2 & \multirow[t]{2}{*}{0.799} \\
\hline & $\geq 200 \mathrm{mg} / \mathrm{dL}$ & 6 & 2 & \\
\hline \multirow[t]{2}{*}{ Triglyceride } & $<150 \mathrm{mg} / \mathrm{dL}$ & 10 & 3 & \multirow[t]{2}{*}{0.639} \\
\hline & $\geq 150 \mathrm{mg} / \mathrm{dL}$ & 4 & 1 & \\
\hline \multirow[t]{2}{*}{ LDL } & $<130 \mathrm{mg} / \mathrm{dL}$ & 5 & 1 & \multirow[t]{2}{*}{0.688} \\
\hline & $\geq 130 \mathrm{mg} / \mathrm{dL}$ & 9 & 3 & \\
\hline \multirow[t]{2}{*}{ HDL } & $<40 \mathrm{mg} / \mathrm{dL}$ & 7 & 2 & \multirow[t]{2}{*}{1.00} \\
\hline & $\geq 40 \mathrm{mg} / \mathrm{dL}$ & 7 & 2 & \\
\hline \multirow[t]{2}{*}{ LDL/HDL } & $<3.5$ & 8 & 1 & \multirow[t]{2}{*}{0.256} \\
\hline & $\geq 3.5$ & 6 & 3 & \\
\hline \multirow[t]{2}{*}{ Chol/HDL } & $<3.5$ & 1 & 0 & \multirow[t]{2}{*}{0.95} \\
\hline & $\geq 3.5$ & 13 & 4 & \\
\hline
\end{tabular}

\section{Discussion}

The gross mean age was $57.4 \pm 15.7$ years in total study population, $60.7 \pm 15.6$ years in stroke (case) group, and $54.2 \pm 16.3$ years in non-stroke (control) group. Mean age was found to be comparable in both groups. In Stroke group, mean age of male was $58.6 \pm 14.5$ years, in female it was $62.8 \pm 15.7$ years while in Non-Stroke group, mean age of male was $53.7 \pm 15.8$ years, in female it was $54.7 \pm 15.9$ years. This age for stroke is matched with study of Debalina Sengupta ${ }^{6}$. Merwyn Fernandes et $\mathrm{al}^{7}$ study shows that increased incidence of stroke patients were found in the age group of 60-69 years which was $32 \%$ followed by $26 \%$ of patients in the age group between 70-79 years. Lemolo $\mathrm{F}$ et al., showed that only $2.5 \%$ of stroke patients were females. ${ }^{8}$

The carotid intima-media thickness (CIMT) was calculated in all the subjects in both Stroke and Non-stroke group. The mean value of CIMT was $0.93 \pm 0.17 \mathrm{~mm}$ in case while $0.72 \pm 0.10 \mathrm{~mm}$ in control with $\mathrm{p}$ value $<0.05$. The depicting that CIMT mean was statistically significantly correlating with case. This is accordance to other studies e.g. Rotterdam Study ${ }^{9}$ indicated that moderate to severe progression of common CIMT was related to age, BMI, male gender, current smoking, systolic blood pressure and hypertension. In ARIC study ${ }^{10}$ suggest that the CIMT serves as a marker of generalized atherosclerosis and it has been positively associated with CAD and stroke of all types. In study of Salim Harris ${ }^{11}$ shows the strong association of the intima-media thickness and stroke $(P=0.008)$ in the Indonesian population. This direct correlation exists because intimamedia thickness is a marker of generalized atherosclerosis. This pathologic vascular phenomenon plays an important role in the pathogenesis of cerebrovascular events such as stroke. 
In our study, when stroke group divided into infarct and hemorrhage and according to Roxana ONUT et al ${ }^{12}$ values of CIMT more than $0.9 \mathrm{~mm}$ are considered abnormal, then we found that 24 patients of infarct have CIMT more than $0.9 \mathrm{~mm}$ and 8 patients have less than $0.9 \mathrm{~mm} .11$ patients of hemorrhage have CIMT less than $0.9 \mathrm{~mm}$ and 7 patients have more than $0.9 \mathrm{~mm}$. Hence, this study suggest that CIMT is more prognostic marker for infarct than hemorrhage,

After correlating lipid profile with CIMT in infarct then we found that, 23 patients have CIMT more than $0.9 \mathrm{~mm}$ with abnormal cholesterol level and $\mathrm{p}$ value statistically significant. 14 patients have CIMT more than $0.9 \mathrm{~mm}$ with abnormal triglyceride level and $\mathrm{p}$ value statistically significant. 23 patients have CIMT more than $0.9 \mathrm{~mm}$ with abnormal LDL level and $\mathrm{p}$ value statistically significant. 18 patients have CIMT more than $0.9 \mathrm{~mm}$ with abnormal LDL/HDL ratio and $p$ value statistically significant. Hence, in this study found that in cholesterol, triglyceride, LDL, and LDL/HDL ratio have positive association with infarct. But in hemorrhage their was no association of lipid profile with CIMT in Stroke group.

In Debalina Sengupta ${ }^{6}$ study also shows a strong positive correlation $(\mathrm{p}<0.001)$ of $\operatorname{Avg} \operatorname{IMT}(\mathrm{cm})$ with Cholesterol $(\mathrm{mg} / \mathrm{dL})$ both in cases $(\mathrm{r}=0.675)$ and controls is $(\mathrm{r}=0.626)$ : Avg $\operatorname{IMT}(\mathrm{cm})$ with LDL:HDL both in cases ( $\mathrm{r}=0.664)$ and controls is $(\mathrm{r}=0.560)$ : concluded that altered lipid profile is associated with cerebral ischemia by increasing carotid intima media thickness (IMT). Among the multiple lipid profiles, the most important factor for increasing average IMT is LDL: HDL. LDL: HDL had already been an important marker for cardiovascular disease but our study shows its importance in relation to cerebrovascular disease (cerebral ischemia).

\section{Conclusion}

We concluded that CIMT and LDL/HDL ratio can be used as screening test for all persons who are at higher risk to get stroke such as diabetes, hypertension, obesity, smoker etc.

\section{References}

1. Wade S Smith, S. Claiborne Johnston J Claude Hemphill, III: Harrison's Priciples of Internal Medicine, Vol. II, $19^{\text {th }}$ edition; McGraw-Hill Education; 2015:Chapter 446 Cerebrovascular Diseases: Page No.2559-2586.

2. Vogel RA, Benitez RM. Noninvasive assessment of cardiovascular risk: From Framingham to the future. Rev Cardiovasc Med 2000; 1:34-42.

3. Lehmann ED, Hopkins KD, Rawesh A, et al. Relation between number of cardiovascular risk factors/ events and non-invasive Doppler ultrasound assessments of aortic compliance. Hypertension 1998; 32:565-9.

4. Endres M, Heuschmann PU, Laufs U, Hakim AM.Primary prevention of stroke: blood pressure, lipids, and heart failure. Eur Heart J 2011; 32:545-552.

5. Bowman T, Sesso H, Ma J, Kurth T, et al. Cholesterol and the Risk of Ischemic Stroke. Stroke 2003; 34:2930-4.

6. Debalina Sengupta, Jayati Bardhan, Anil Baran Singha Mahapatra Joyshree Banerjee and Jayanta Kumar Rout; Correlation between lipid profile and carotid intima media thickness in cerebral ischemia: Indian $J$ Physiol Pharmacol 2014; 58(4) : 354-364.

7. Merwyn Fernandes et al, Common Carotid Artery Intima Media Thickness Measurement in Cerebral Ischemic Stroke Patients Using Ultrasonography: A Prospective Study. International Journal of Anatomy, Radiology and Surgery. 2016 Jul, Vol-5(3): RO19-RO23.

8. Lemolo F, Martinis A, Dteinman DA, Spence JD. Sex differences in carotid plaque and stenosis. Stroke. 2004; 35(2): 477-81. 
9. Hollander M, Hak AE, Koudstaal PJ, et al. Comparison between measures of atherosclerosis and risk of stroke: the Rotterdam Study. Stroke 2003; 34: 23672372.

10. Chambless LE, Folsom AR, Clegg LX, et al. Carotid wall thickness is predictive of incident clinical stroke: the Atherosclerosis Risk in Communities (ARIC) study. Am J Epidemiol 2000; 151: 478-487.

11. Sima AV, Stancu CS, Simionescu M. Vascular endothelium in atherosclerosis. Cell Tissue Res 2009;335:191-203.

12. Roxana ONUT, Dana Constantinescu et al. Imaging Atherosclerosis by Carotid Intima-media Thickness in vivo: How to, Where and in Whom?; A Journal of Clinical Medicine, Volume 7 No.2 2012. 